\title{
No Food Allowed - The Latest Virtual Reality Laboratory Accident
}

\author{
John T. Bell and H. Scott Fogler \\ University of Illinois Chicago / University of Michigan Ann Arbor
}

The authors of this paper are in the middle of a multi-year project to create, distribute, and evaluate a series of virtual reality based laboratory accidents, with the dual goals of promoting lab safety and determining the optimal applicability of this medium for this purpose. This paper describes the current status of the project, with special emphasis on the most recently developed accident, involving food in a laboratory.

\section{Introduction}

People who are given a long list of written laboratory safety rules will follow those rules for only a certain length of time before they become complacent and forgetful. Anyone who has ever experienced an actual accident, however, will remember that experience much longer than any set of written rules. Obviously, it is not practical to deliberately cause accidents just to illustrate and emphasize lab safety procedures. Virtual reality offers an alternative that lies somewhere between written rules and real experiences for its overall effectiveness.

Virtual reality, ( VR ), is an interactive immersive three-dimensional computer technology with the overall goal of creating a first-person experiential simulation so realistic and believable that users cannot distinguish it from the real thing. In practice, different implementations of VR approach this goal to a greater or lesser extent. High-end ( multi-million dollar ) systems can indeed produce simulations sufficiently effective to make users forget that it is just a simulation. Low-end ( student-affordable ) systems are not nearly as effective, but are continuously improving as personal computer speeds and graphics cards improve, and as special VR technology becomes more readily available to the consumer market.

The primary goal of the current project is to develop a series of VR-based laboratory accidents, in a variety of student accessible formats. A set of lab safety rules has been selected that are both commonly applicable to a wide variety of laboratory settings and also practicable to implement using VR. For each rule, users have the option of either obeying the rule or not, and then experiencing first-hand the resulting consequences. A second goal of the project is to experiment with different implementations of VR, to determine which is ( are ) the most effective for delivering the desired experience to the intended audience.

This project was originally started at the VRiChEL ( Virtual Reality in Chemical Engineering Laboratory ) in the Department of Chemical Engineering at the University of Michigan[1], and is now continuing at the VRUPL ( Virtual Reality Undergraduate Projects Laboratory ) at the University of Illinois Chicago[2]. Project results and other information are freely available from the VRUPL web site[2]. 


\section{Platforms Under Development}

Different implementations of VR have different features and benefits, which make them more or less effective for this purpose. The following implementations are currently being used, under a comparative and experimental basis.

\section{- VRML}

The Virtual Reality Modeling Language, VRML, is an extension to HTML for the description of three-dimensional interactive objects and environments. The benefit of VRML is that anyone can run the simulations from their web browser, once they have downloaded the appropriate plug-in. The disadvantages are that the simulations do not support any VR devices, may run slowly on some systems, and do not necessarily perform identically on all systems. Timing related issues in particular are especially difficult to control consistently.

\section{- WorldToolKit}

WorldToolKit, WTK, is a library of C language functions for the development of VR programs, developed by the Sense8 Corporation, which is now a division of UGS[3]. These libraries are available for several different platforms ( Silicon Graphics, Windows based PCs, Linux, Macintosh ), support a wide range of VR hardware, and handle most of the low-level device interface and simulation management tasks. The resulting programs are binary executables that run faster with better timing control than VRML simulations. The disadvantage is that the user must download and install the appropriate version of the simulations for his or her particular hardware.

\section{- WorldUp}

WorldUp is an alternative product from Sense8 / UGS that features a graphical development environment instead of $\mathrm{C}$ Programming. The resulting simulations are run in a custom player, which is also available as a plug-in for web-based delivery. The compatibility of WorldUp and WorldToolKit makes it suitable for rapid development and initial prototyping, but this has not yet been fully implemented in the VRUPL laboratory.

\section{- Java3D}

Java3D is a set of Java classes for the development of Java programs involving interactive three-dimensional objects and environments. This platform shows particular promise since Java programs can be either binary applications or web-based applets, and because Java is a C++ like language taught in university courses. Work has just commenced on the first simulation using this platform, and therefore its overall usefulness to this project has not yet been determined.

\section{Overall Project Status}

Table 1 summarizes the current status of the lab accidents project, with explanatory notes given in the following numbered notes. Note that some of these scenarios have been reported in previous ASEE papers[4-6]. 


\begin{tabular}{|c|c|c|c|c|}
\hline \multirow{2}{*}{$\begin{array}{l}\text { Safety }^{1} \\
\text { Rule }\end{array}$} & \multicolumn{4}{|c|}{ Platform } \\
\hline & VRML & WorldToolKit & WorldUp & Java3D \\
\hline Wear Safety Glasses & Done $^{2}$ & Done & $\begin{array}{l}\text { Under }^{3} \\
\text { Development }\end{array}$ & \\
\hline Store Chemicals Properly & Done & & & \\
\hline No Food in Lab & $\begin{array}{l}\text { Under }^{4} \\
\text { Revision }^{2}\end{array}$ & Done & & \\
\hline Keep Aisles Clear & $\begin{array}{l}\text { Under } \\
\text { Revision }\end{array}$ & & & $\begin{array}{l}\text { Under } \\
\text { Development }\end{array}$ \\
\hline Secure Gas Cylinders & & $\begin{array}{l}\text { Under } \\
\text { Development }\end{array}$ & Incomplete $^{5}$ & \\
\hline Proper Attire & & $\begin{array}{l}\text { Under } \\
\text { Development }\end{array}$ & & \\
\hline Know Locations & & $\begin{array}{l}\text { Under } \\
\text { Development }\end{array}$ & & \\
\hline No HorsePlay & & & & \\
\hline Virtual Reactor & NA & $\begin{array}{l}\text { Under } \\
\text { Development }\end{array}$ & NA & NA \\
\hline SafeHunt & NA & Done & NA & NA \\
\hline
\end{tabular}

Table 1 - Current Status of Virtual Reality Laboratory Accident Scenarios

Explanatory Notes:

1. The following Rules are either implemented or planned:

- Always Wear Safety Glasses in the Laboratory - A hose breaks loose from an experiment, spraying the user in the face, with more serious consequences when glasses are not worn.

- Always Store Chemicals Properly - The user must clean up the lab, storing acids away from bases, flammables in the flammables storage cabinet, etc. properly before disaster strikes.

- No Food or Drink Allowed in the Laboratory - A leaky hose drips into a soda can. ( See Below. ) 
- Always Keep Aisleways Clear - The user discovers the difficulty in evacuating a cluttered lab in an emergency.

- Always Fasten Compressed Gas Cylinders - Otherwise they can become flying torpedoes if the nozzle should break off.

- Always Wear Proper Attire in the Laboratory - Long hair, loose clothing, and improper footwear can all leave the wearer susceptible to injury.

- Know the Locations of Emergency Equipment and Exits - Users must promptly locate a fire extinguisher, safety shower, or emergency exit in order to avoid catastrophe.

- No Horseplay allowed in the Laboratory - The consequences could be far more serious than intended.

- Virtual Reactor - The virtual reactor simulation is a more advanced application that is not really a laboratory accident, although it is related. This application simulates the operation of a nitroaniline production facility, whose explosion in 1971 has been the subject of several safety studies [7-10]. For this simulation students must design and operate the reactor in the most efficient manner possible, with potentially explosive results if their calculations are in error.

- Safety Scavenger Hunt - This application is also not really a laboratory accident, and was in fact developed under an earlier funded project. However, it is safety related, and is therefore being distributed through the lab accidents web site to increase visibility. This simulation involves searching for and evaluating safety-related issues in a chemical production facility, and is suitable for use in a process design or chemical process safety course [5].

2. The modules marked "Done" are available for public access on the VRUPL web site, ( http://www.vrupl.evl.uic.edu ), and are not undergoing any current or planned revisions. They may be revisited at a later date.

3. The modules marked "under development" are currently being developed, primarily by a new batch of students who joined the VRUPL lab in January 2002. Hopefully some of these applications will be available by the time this paper is presented.

4. The "no food" and "keep aisleways clear" VRML modules were the first two modules originally created and placed on the web, but are currently being revised to improve their overall effectiveness.

5. Development of the gas cylinders module in the WorldUp format was started but never completed by a student who has since graduated and left the university. It is planned to assign the completion of this project to another student at some point in the future. 


\section{No Food Allowed - The Latest Development}

This accident scenario focuses on the safety rule that food and drink should never be present in a laboratory setting. For this application, the user must decide before entering the laboratory whether or not to obey the safety rule. Upon entering the laboratory, the user encounters a soda can that has been left on the lab bench ( Figure 1A ). What is not immediately obvious is that the adjacent chemical experiment has a leaky hose, which is dripping an unidentified liquid into the open soda can. When the user approaches to within a certain proximity of the can, one of two events automatically occurs.

If the user has chosen to obey the rules, then a hand reaches out, grabs the soda can, and throws the can into a nearby trash can. At that point the trash can erupts into flames and a message appears expressing relief that the beverage was not consumed ( Figure 1B ).

If the user has chosen to disobey the rules, then the hand that reaches out brings it up to the user's lips ( Figure 1C ). The user's view then spirals down to a position looking up from the floor and fades to black ( Figure 1D ). A message scrolls across the solid black screen indicating that the user is seriously ill and possibly dead.

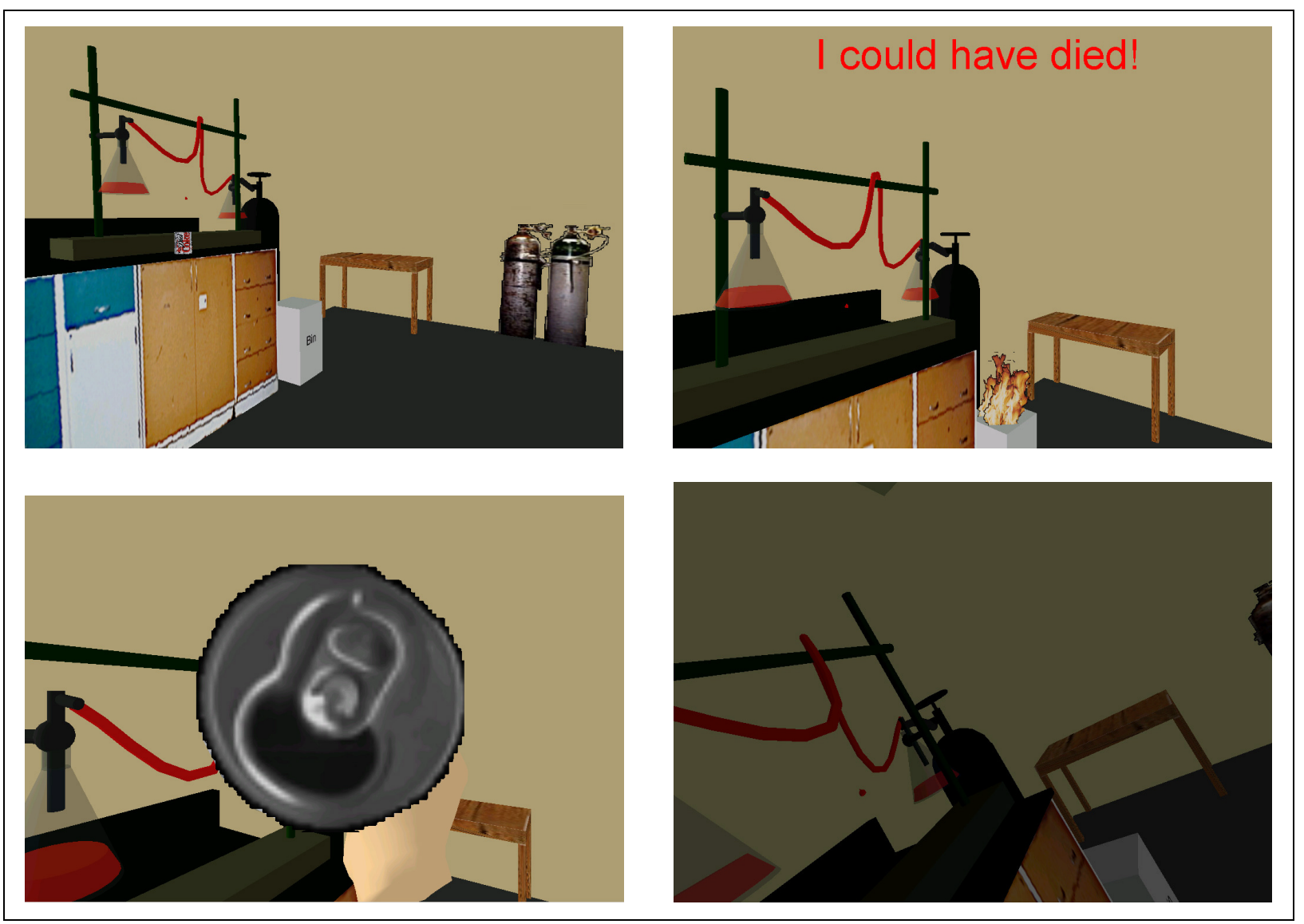

Figure 1 - Four views of the "No Food" module. A: A soda can in the wrong place.

B: Discarded, it starts a trash fire. C: But when drunk ... D: The user spirals down to oblivion! 


\section{Conclusions}

A series of virtual reality based laboratory accidents have been developed, and others are currently under development, in a variety of different formats. VRML, WorldUp, and Java3D formats allow applications to run in web browsers, but do not support special hardware and do not allow accurate control timing related issues. WorldToolKit applications produce binary compiled programs, which must be downloaded and installed on users' machines for specific hardware and operating system environments. Students tend to prefer developing WorldToolKit applications, as it allows them to use the $\mathrm{C}$ programming skills that they have acquired in their computer science courses. The modules are available for free access from the VRUPL web site[2].

\section{Acknowledgements}

The authors wish to gratefully acknowledge the efforts of the undergraduate student programmers who have assisted in the development of the projects described in this paper, specifically Nipa Patel, Arun Rao, Max Kerper, Sara Swamy, Jonathon Miyamoto, Suet Leong, David Anaglate, Suhag Patel, Luis Bravo, Petre Brotea, Adina Iclozan, James Angelo, Matt Moersfelder, Christine Cha, Sharon Ohba, Michael Cataletto, Rob King, Tim Mygatt, Michelle Westbrook, Paul Sonda, Anita Sujarit, and Scott Whitney ( in reverse chronological order. ) Thanks are also due to John Jechura and Tom Pakula of Marathon Oil Company and to Dr. Joseph Louvar and Lawrence James of BASF Chemical Corporation for the valuable resources they have provided for the development of the virtual reality modules. The National Science Foundation ( DUE-9972302, DUE- 9555094 ), The Department of Chemical Engineering at the University of Michigan, The Department of Computer Science at the University of Illinois Chicago ( UIC ), and the Electronic Visualization Laboratory at UIC have all contributed financially to this project.

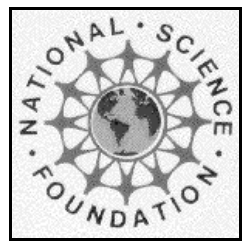

This project was supported, in part

by the

\section{National Science Foundation}

Opinions expressed are those of the authors and not necessarily those of the Foundation

\section{Bibliographical References}

1. Bell, John T., "Virtual Reality in Chemical Engineering Laboratory Web Site", http://www.vrupl.evl.uic.edu/vrichel.

2. Bell, John T., "Virtual Reality Undergraduate Projects Laboratory Web Site", http://www.vrupl.evl.uic.edu.

3. Sense8 Corporation, "Sense8 Corporation Web Site", http://www.sense8.com.

4. Bell, John T. and H. Scott Fogler. "Virtual Reality Laboratory Accidents". Proceedings of American Society for Engineering Education Annual Conference, Albuquerque, NM, American Society for Engineering Education, 2001.

5. Bell, John T. and H. Scott Fogler. "A Virtual Reality Based Safety and Hazard Analysis Simulation". Proceedings of American Society for Engineering Education Annual Conference, St. Louis, MO, American Society for Engineering Education, 2000.

6. Bell, John T. and H. Scott Fogler. "Virtual Laboratory Accidents Designed to Increase Safety Awareness". Proceedings of American Society for Engineering Education Annual Conference, Charlotte, NC, American Society for Engineering Education, 1999. 
7. Willey, Ronald J., et al., "Thermo-Kinetic Analysis of Reactions Involved in the Manufacture of oNitroaniline", Process Safety Progress, 20(2), pp 123-129, 2001.

8. Rodrigues, Fausto M., "Examination of Exothermic Reactions Involved in the o-Nitroaniline Synthesis Reaction", Master of Science Thesis, Department of Chemical Engineering, Northeastern University, Boston, MA, 2000.

9. Vincent, G.C., "Rupture of a Nitroaniline Reactor", Loss Prevention, 5 pp 46-52, 1971.

10. Willey, Ronald J., "Seminar on a Nitroaniline Reactor Rupture", 1994, SACHE, American Institute of Chemical Engineers: New York, NY.

\section{Biographical Information}

\section{John T. Bell}

( Lecturer, Department of Computer Science, University of Illinois, Chicago, 312 413-9054, JBell@uic.edu, http://www. cs.uic.edu/ jbell ) Dr. Bell holds graduate degrees in Chemical Engineering and Computer Science, and combines both skills by developing computer simulations of chemical engineering related phenomenon. Recent work has focused on the application of interactive immersive three-dimensional display technology (a.k.a. VR) to the presentation of scientific, engineering, and educational information.

\section{H. Scott Fogler}

( Vennema Distinguished Professor of Chemical Engineering, University of Michigan, H.Scott.Fogler@ umich.edu, http://www.engin.umich.edu/dept/che/people/fogler.html. ) Dr. Fogler is the author of four books and over 160 research publications. Awards include the ASEE Meriam-Wiley Distinguished Author Award (1996), the University of Michigan Distinguished Faculty Achievement Award (1996), the AIChE Warren K. Lewis Award (1995), and the Chemical Manufacturer's Association National Catalyst Award (1999). 